\title{
PROGESTERONE LEVELS IN OVARIAN VENOUS BLOOD DURING THE OESTROUS CYCLE OF THE COW
}

\author{
W. DOBROWOLSKI, ELŻBIETA STUPNIGKA AND E. DOMAŃSKI \\ Institute of Animal Physiology and Nutrition, Jabtonna, near Warsaw, Poland
}

(Received 5th April 1967, revised 9th Fune 1967)

\begin{abstract}
Summary. Progesterone levels were determined in ovarian venous blood of nine cows with regular oestrous cycles and in three cows with prolonged maintenance of the corpus luteum. The ovarian venous blood was collected by chronic cannulation of the ovarian vein, through the anterior uterine vein. The progesterone level increased from 5.6 $\mu \mathrm{g} / 100 \mathrm{ml}$ plasma on the lst day of the oestrous cycle to about 125 $\mu \mathrm{g} / 100 \mathrm{ml}$ on the 8 th day and to about $180 \mu \mathrm{g} / 100 \mathrm{ml}$ on Days 14 and 15 of the cycle. Thereafter, the level rapidly decreased to 10 to $20 \mu \mathrm{g} / 100$ $\mathrm{ml}$ on the day of ovulation. In cows with prolonged maintenance of the corpus luteum when ovulation did not occur, the progesterone levels did not decrease and were as high as the highest luteal phase levels in cows with regular cycles. According to the data obtained, progesterone levels in ovarian blood of non-pregnant cows seem to reflect the luteal function of the ovary during the oestrous cycle.
\end{abstract}

\section{INTRODUCTION}

On the basis of numerous experiments carried out on various species of animals it has been suggested that progesterone given in high doses inhibits, while in very small doses induces, ovulation (cf. Rothchild, 1965). This regulating action of progesterone should be reflected in its ovarian secretion rate throughout the oestrous cycle. However, this phenomenon has not been studied in great detail. In laboratory animals the technical limitations have resulted in the secretion of progesterone being estimated mainly indirectly by analysis of progesterone in the corpus luteum. Copious literature on this subject in human beings presents data on the levels of progesterone in peripheral blood and the production rates during the menstrual cycle, and also on a progesterone metabolite (pregnanediol) in the urine. In farm animals, our data concerning the ovarian secretion rate of progesterone throughout the oestrous cycle are mainly based on determinations of progesterone in the corpus luteum and on fragmentary determinations of the secretion rate of this hormone in ovarian venous blood on some days of the oestrous cycle. Among numerous papers on this subject Gomes, Estergreen, Frost \& Erb (1963) in the bovine, Edgar \& Ronaldson (1958) and Short (1964) in sheep by acute experiments, McCracken \& Goding (1966) in sheep using a jugulo-carotid ovarian autotransplant and Gomes, 
Hersehler \& Erb (1965) in the sow, estimated progesterone levels in the ovarian venous blood throughout the oestrous cycle. However, Gomes et al. (1965), in the sow, were only able to present the levels of progesterone in the ovarian venous blood in the form of a complete curve reflecting all phases of the oestrous cycle. It is clear that a quantitative analysis of progesterone in the corpus luteum as well as secretion rates of this hormone determined on some days of the oestrous cycle, carried out by acute experiments, cannot give a true account of the ovarian secretion of progesterone throughout the whole period of the oestrous cycle. Therefore, we undertook some experiments on unanaesthetized cows and have been able to develop a surgical technique for serial sampling of ovarian venous blood.

\section{MATERIALS AND METHODS}

\section{Collection of ovarian venous blood}

Eleven 3- to 6-year-old cows of the black and white Friesian breed were used and their ovarian veins were cannulated for the collection of ovarian venous blood. Every cow was observed for oestrous behaviour for three cycles before operation and only animals with regular cycles were used in the experiment. Oestrus and ovulation were checked by (a) external signs, (b) rectal palpation and (c) vaginal smears stained according to Papanicolaou. The blood is supplied to the ovary by the ovarian branch of the internal spermatic artery (see Pl. 1, Fig. 1). The ovarian veins, two or three in number at the beginning, run along with the ovarian artery in ligamentum latum uteri; then they join together and form one big vessel, the common ovarian vein. The anterior uterine vein joins this vessel forming the utero-ovarian vein, which drains the blood from the ovary and from some parts of the uterus.

The principle of cannulation consists in the introduction of a cannula into the anterior uterine vein; when introducing a cannula into the anterior uterine vein care should be taken not to block the junction of this vein with the ovarian vein (see Pl. 1, Fig. 1), because this would occlude the blood outflow from the ovary.

The operation was carried out in anaesthetized animals; anaesthesia was induced by the intramuscular injection of Combelen [ $\mathrm{N}$-(3'-dimethylaminopropyl)-3-propionyl-phenotiazin, 'Bayer'] in a dose of $0.02 \mathrm{mg} / \mathrm{kg}$ body weight, and continuous intravenous infusion of $10 \%$ chloral hydrate during the course of the operation. The abdomen was opened in the right flank and, after examination of the ovaries, cannulation of the anterior uterine vein was carried out. A silicone cannula (1 $\mathrm{mm}$ internal bore and $2 \mathrm{~mm}$ external bore) was introduced into the anterior uterine vein and fixed by ligatures. Then the cannula was exteriorized, filled with diluted heparin (500 i.u. in $1 \mathrm{ml}$ of saline) and clamped off. All veins draining into the anterior uterine vein were ligated to prevent the dilution of ovarian effluent. The incision of the abdomen was sutured and the cannula was taped to the loin. The cannula after the operation was perfused with diluted heparin (500 i.u. in $1 \mathrm{ml}$ ) at 2-hr intervals. This procedure enabled us to prevent blood clotting in the cannulated vein and to collect the blood for 4 to 9 days without treating the whole animal with heparin. 


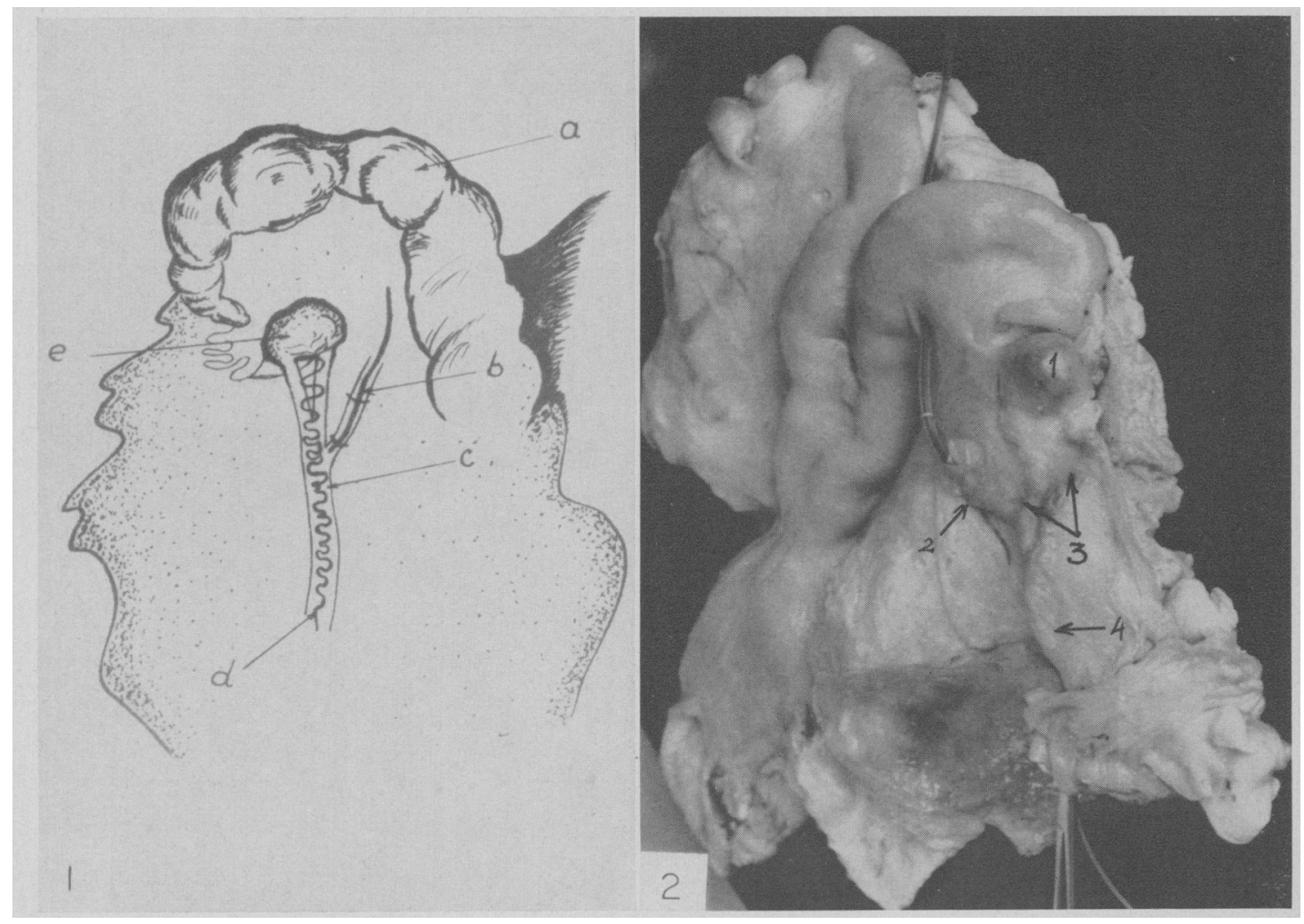

Frc. 1. Diagram of blood vessels of the ovary; a-uterine horn: b-anterior uterine vein with catheter in place; $c$-utero-ovarian vein; $d$-ovarian plexus; e-ovary.

FIG. 2. Uterus and broad ligament in natural position with cannula inserted into the anterior uterine vein; the frec end of the cannula is exteriorized during the operation. 1-ovary; 2-anterior uterine vein; 3 -ovarian vcin; 4-utero-ovarian vein (One of the preparations removed when the experiment was finished and the cow was slaughtered.) 
Blood was collected by inserting a needle into the distal end of the cannula and drawing the blood into a syringe by negative pressure. Blood samples of $100 \mathrm{ml}$ were taken four times a day at $6-\mathrm{hr}$ intervals; they were immediately chilled and centrifuged at $4^{\circ} \mathrm{C}$. All four plasma samples were pooled and thus a representative sample was obtained for $24 \mathrm{hr}$. Daily collections of plasma were frozen and stored at $-15^{\circ} \mathrm{C}$ until assayed.

In a few preliminary cases the blood flow rate from the ovary was measured; a pneumatic cuff made of silicone rubber was placed around the utero-ovarian vein below the inserted cannula, and this pneumatic cuff was connected by a thin piece of tubing, which was exteriorized. This made it possible to occlude the vein at the time of collection, and so to collect all the effluent blood from the ovary. This arrangement, however, produced inflammation of the uteroovarian vein and consequently completely blocked the blood flow in this vein within 2 days of the operation. The method was therefore not used again.

\section{Determination of progesterone in the ovarian blood plasma}

Progesterone was determined as the 2,4-dinitrophenylhydrazone using the method of Stupnicki \& Stupnicka (1963), modified by Stupnicka. This modification consisted of additional purification of crude neutral extracts of blood plasma by means of column partition chromatography on silica gel. $4-{ }^{14} \mathrm{C}$ progesterone was included as an internal recovery standard; the mean recovery was $52 \%$; the sensitivity was shown to be $0.5 \mu \mathrm{g}$ of progesterone. The precision of the method, expressed as standard error in extinction units, was 0.013 , while in quantities of progesterone it was $0.15 \mu \mathrm{g}$ (range 2 to $12 \mu \mathrm{g}$ of progesterone in the sample).

\section{RESULTS}

Owing to the fact that the cannulated vein could only be kept patent for 4 to 9 days, the animals for the experiment were selected in consecutive phases of their oestrous cycles, namely: Days 3 to 9 , Days 8 to 16 and Days 15 to 21 or 22 .

In nine out of eleven cannulated cows the oestrous cycles were regular; the length of the cycles was 20 to 22 days. In two cows, however, disturbances in the cycles occurred: they showed no signs of ovulation and their corpora Iutea were maintained beyond the normal time. No other pathological changes in the reproductive organs of these cows were found.

\section{Progesterone levels in ovarian blood plasma of cows with regular cycles}

The values are presented in Text-fig. 1. The lowest levels of progesterone (on the average $5.6 \mu \mathrm{g} / 100 \mathrm{ml}$ ) were found on Days 1 to 4 of the cycle. On the 4 th day the hormone level started to rise and increased to about $125 \mu \mathrm{g} / 100 \mathrm{ml}$ by the 8 th day of the cycle. Then, on Days 9 to 11 of the cycle a fall lasting 2 to 3 days was observed. Furthermore, on Days 10 to 11 a second, very rapid and continuous rise in the level occurred which reached its peak (on the average $166 \mu \mathrm{g} / 100 \mathrm{ml}$ ) on the 14 th to 15 th day of the cycle. This highest level was maintained for $24 \mathrm{hr}$ only, then a continuous decline was observed until the day of ovulation. 


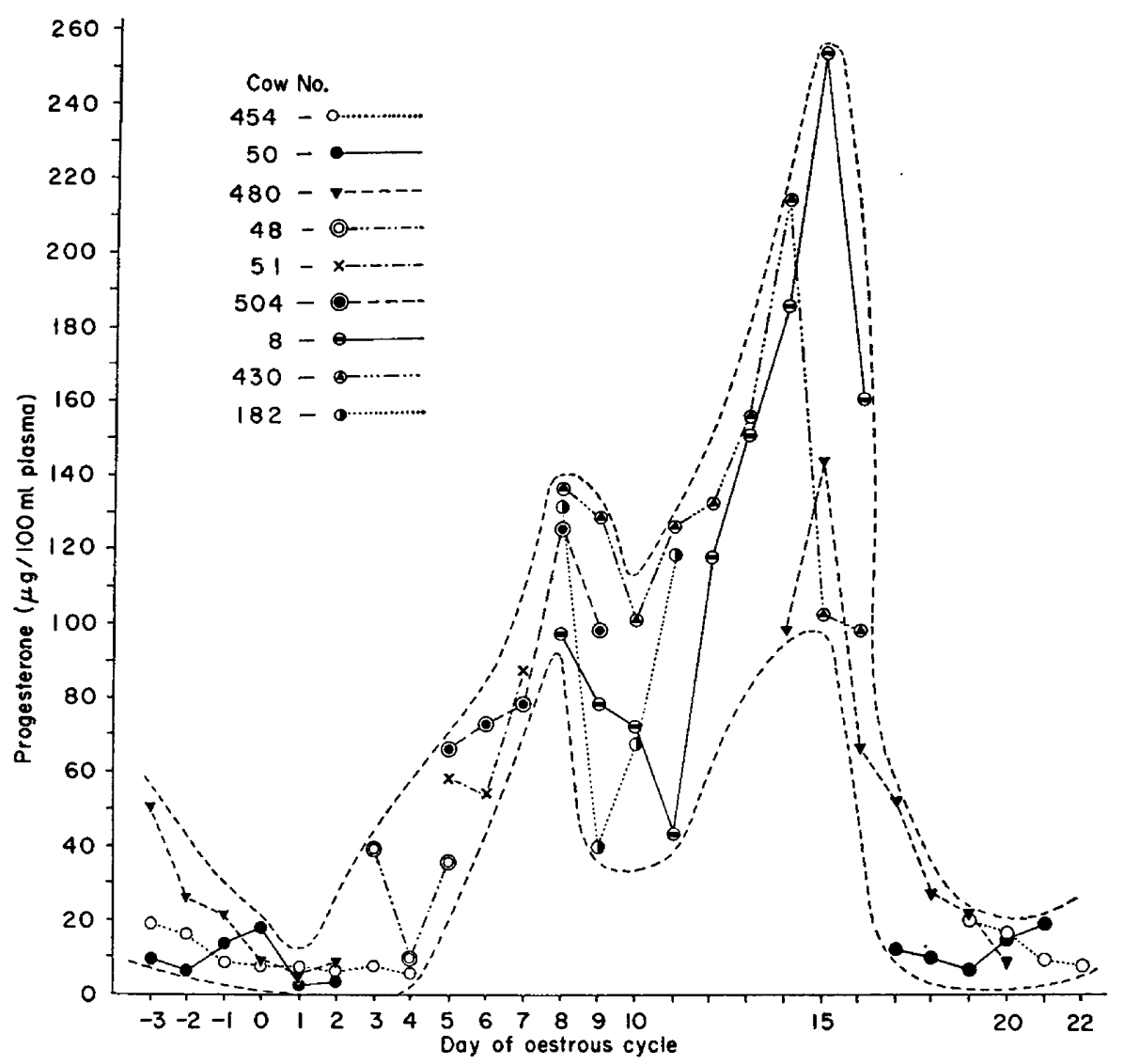

Text-FIG. 1. Concentration of progesterone in the ovarian venous blood of individual cows with regular oestrous cycles at various phases of the cycle. The two continuous dotted lines represent the range of values found.

Progesterone levels in ovarian blood plasma of cows with a persistent corpus luteum

As mentioned above, two cannulated cows (Nos. 200 and 220), failed to show oestrus or ovulation at the expected time. Rectal palpation revealed no developing Graafian follicles and maintained corpora lutea. For comparison, a cow (No. 234) was chosen from the herd of the experimental farm which for 95 days had shown no symptoms of heat or ovulation and had a persistent corpus luteum. The state of the ovaries in this cow was confirmed by visual examination during

TABLE 1

PROGESTERONE LEVELS IN OVARIAN BLOOD PLASMA OF COWS WITH PERSISTENT CORPORA LUTEA

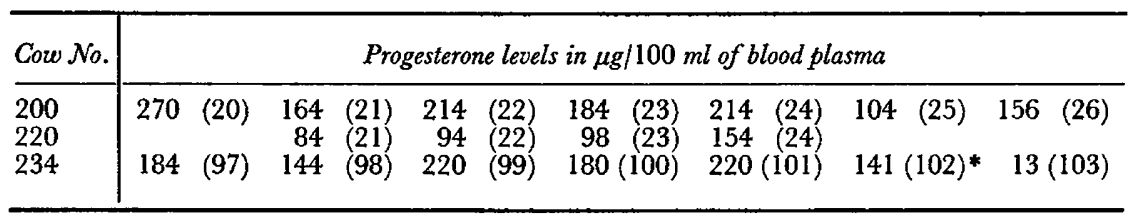

Days of oestrous cycle in parentheses.

* Enucleation of corpus luteum. 
cannulation of the ovarian vein. From all these three cows ovarian venous blood was collected for a period of 4 to 7 days. After 6 days, in cow 234, the corpus luteum was enucleated through the rectum. Table 1 shows the progesterone levels in these cows. These values did not decline before the expected date of oestrus, but were maintained at normal luteal-phase levels. Cow 234, with a persistent corpus luteum, also showed a high level of progesterone $(155 \mu \mathrm{g} / 100$ $\mathrm{ml}$ ), which rapidly decreased after its enucleation (to $13 \mu \mathrm{g} / 100 \mathrm{ml}$ ).

\section{DISGUSSION}

The question arises whether the levels of progesterone obtained from animals used in consecutive phases of the cycle, lasting 4 to 9 days for particular individuals only, are representative of the normal oestrous cycle. It seems likely that this is the case, since consecutive phases of the cycle in particular animals overlapped each other in time, and the curves of particular animals, despite individual variations in their levels, showed similarities in shape and character. Moreover, analysis of variance showed that the differences in the levels of progesterone between particular cows throughout the oestrous cycle were not statistically significant (homogeneity of variance, $P<0.05$ ). Thus the designed curve may be accepted as representing the levels of progesterone in the ovarian venous blood throughout the oestrous cycle of the bovine.

The difference in method of collecting the blood samples and in the levels of progesterone in ovarian venous blood obtained in the form of a characteristic curve makes it difficult to compare the results of this study with those of Gomes et al. (1963), which were based on the analysis of single samples taken from particular animals in acute experiments. Despite this fact, however, some points (values) of the curve are in accordance with the results presented by Gomes et al. (1963).

Our results suggest a direct association between the levels of progesterone in the ovarian venous blood, the growth in weight of the corpus luteum, and its concentration of progesterone. Gomes et al. (1963) reported a gradual increase in corpus luteum weight between Days 1 and 6 , followed by a large increase in weight between Days 7 and 8, while Cupps, Laben \& Mead (1959) reported a gradual luteinization of the granulosa cells of the corpus luteum during the first 5 days and luteinization of theca interna cells between Days 8 and 12 of the cycle. A gradual increase in the concentration of progesterone in the corpus luteum was also found during this phase by numerous authors, reaching its highest values between Days 14 and 16 of the cycle (Erb \& Stormshak, 1961; Mares, Zimbelman \& Casida, 1962; Gomes et al., 1963). On the other hand, the rapid decline of ovarian venous progesterone concentration on the 15th or 16th and subsequent days of the cycle seems to be closely associated with atrophic changes in luteal cells and a considerable decrease in the concentration of progesterone in luteal tissue. These findings suggest that the development, maintenance and activity of the corpus luteum closely parallel changes in the concentration of progesterone in the ovarian venous blood. This suggestion may be supported also by the high level of progesterone in the ovarian blood in cows 
with a permanent corpus luteum; the level in these cows was maintained as high as during the luteal phase of the regular cycle.

While the progesterone concentration in the ovarian venous blood and the activity of the corpus luteum seem to be associated with each other, these events are in a reciprocal relationship to the development and growth of Graafian follicles. Histological examinations of the ovary (Cupps et al., 1959; Asdell, 1960; Bane \& Rajakosky, 1961) showed triphasic growth of the Graafian follicles during the oestrous cycle. The first phase of the growth was observed on Days 3 to 5 of the cycle, the second one on Days 9 to 11 and the third during the last days of the cycle (before ovulation). Thus, the present facts indicate that the regulating action of progesterone on the oestrous cycle is reflected in the ovarian secretion rates of this hormone within some phases of the oestrous cycle. It is possible to correlate low or high concentrations of progesterone in the ovarian blood with acceleration or inhibition in the growth of the Graafian follicles respectively. These results, however, do not suggest an inducing action of progesterone on ovulation, for the pre-ovulaton concentration of this hormone in the ovarian blood showed a decrease in all but one of the cows.

\section{ACKNOWLEDGMENT}

The authors are greatly indebted to $\mathrm{Dr} \mathrm{R}$. V. Short for reading the manuscript and correcting its English and also for providing helpful criticism.

\section{REFERENCES}

Asdele, S. A. (1960) Growth in the bovine Graafian follicle. Cornell Vet. 50, 3.

Bane, A. \& Rajakoski, E. (1961) The bovine estrous cycle. Cornell Vet. 51, 1, 77.

Cupps, P. T., Laben, R. C. \& Mead, S. W. (1959) Histology of pituitary, adrenal and reproductive organs in normal cattle and cattle with lowered reproductive efficiency. Hilgardia, 29, 383.

Edgar, D. G. \& Ronaldson, J. W. (1958) Blood levels of progesterone in the ewe. F. Endocr. 16, 378.

ERB, R. E. \& STormshaK, F. (1961) Progestins in corpora lutea, ovaries and adrenals after breeding of normal and abnormal cows. 7. Dairy Sci. 44, 888.

Gomes, W. R., Estergreen, V. L., Frost, O. L. \& Erb, R. E. (1963) Progestin levels in jugular and ovarian venous blood, corpora lutea and ovaries of the non-pregnant bovine. F. Dairy Sci. 46, 553.

Gomes, W. R., Hersehler, R. C. \& Erb, R. E. (1965) Progesterone levels in ovarian venous effluent of the nonpregnant sow. F. Anim. Sci. 24, 722.

Mares, S. E., Zimbelman, R. G. \& Casida, L. E. (1962) Variation in progesterone content of the bovine corpus luteum of the estrual cycle. F. Anim. Sci. 21, 266.

McCracken, I. A. \& Goding, I. R. (1966) Progesterone secretion by the jugulo-carotid ovarian autotransplant in sheep. 2nd int. Congr. Hormonal Steroids, Milan. Excerpta med. No. $111,473$.

RoтнсніLD, I. (1965) Interrelation between progesterone and the ovary, pituitary and central nervous system in the control of ovulation and the regulation of progesterone secretion. Vitams Horm. 23, 233.

Short, R. V. (1964) Ovarian steroid synthesis and secretion in vivo. Recent Prog. Horm. Res. 20, 303.

StuPNICKI, R. \& STUPNICKA, E. (1963) Quantitative analysis of ketosteroids by means of paper chromatography. Nature, Lond. 200, 165. 